\title{
Kinetic Analysis Uncovers Hidden Autocatalysis and Inhibition Pathways in Titanium(III)-Catalyzed Ketone-Nitrile Couplings
}

\author{
Sara L. Younas and Jan Streuff*
}

Cite This: ACS Catal. 2021, 11, 11451-11458

Read Online

ABSTRACT: Through kinetic analysis, we demonstrate that the formation of catalyst and substrate reservoirs plays a crucial role in the titanium(III)-catalyzed ketone-nitrile coupling reaction. Together with the insight from previous studies, a kinetic model is assembled that reflects the observed influence of $\mathrm{ZnCl}_{2}$ and $\mathrm{Et}_{3} \mathrm{~N}$ byproducts as well as the hydrochloride additive, which is employed frequently in titanium(III) catalysis. We further propose for the $\mathrm{Cp}_{2} \mathrm{TiCl}_{2}$-catalyzed reaction that the acceleration phase of the reaction originates from a hidden autocatalytic cycle, which leads to a change in the rate-determining step over the course of the reaction.

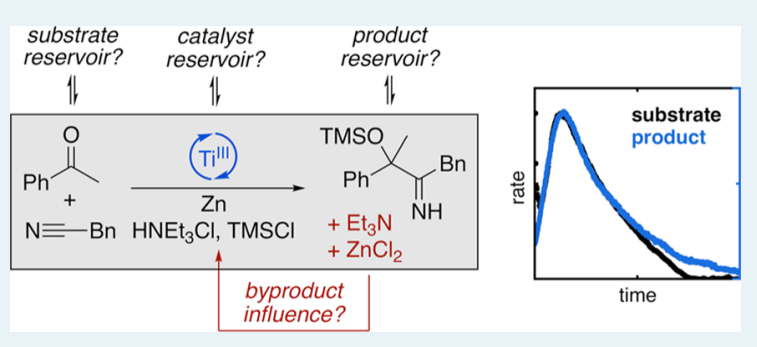

KEYWORDS: catalysis, kinetic analysis, reductive coupling, titanium, umpolung

\section{INTRODUCTION}

Titanium(III)-mediated and -catalyzed reactions enable the reductive construction of otherwise difficult-to-form carboncarbon bonds. ${ }^{1,2}$ Consequently, they have found increasing application in organic synthesis over the past 30 years. $^{3}$

Following the pioneering works on titanium(III)-promoted and -catalyzed epoxide openings, -pinacol couplings, and -related reactions, ${ }^{4}$ our group has investigated catalyticreductive Umpolung reactions in form of cross-couplings between Michael acceptors, ketones, imines, and nitriles. ${ }^{16,5}$ More recently, we have reported titanium(III)-catalyzed decyanations and desulfonylations. ${ }^{6}$ The catalytic systems of titanium(III)-catalyzed reactions, however, are complex and additives such as amine or pyridine bases, amine hydrochlorides, and chlorotrimethylsilane have a strong effect on the reaction outcome. ${ }^{4-7}$ Moreover, $\mathrm{ZnCl}_{2}$ or $\mathrm{MnCl}_{2}$, which are formed as byproducts of the turnover-enabling catalyst reduction with $\mathrm{Zn}$ or $\mathrm{Mn}$, have an effect on the reactions as well. As a matter of fact, a strong influence of $\mathrm{ZnCl}_{2}$ or $\mathrm{MnCl}_{2}$ has been observed in earlier examples of epoxide opening/ radical additions to Michael acceptors, and it was concluded that these salts either led to highly coordinated transition states or acted as Lewis acid cocatalysts (Scheme 1$){ }^{8}$ Independently, we have observed a strong beneficial effect of $\mathrm{ZnCl}_{2}$ in catalytic decyanation reactions and discovered that the $\operatorname{zinc}($ II) salt prevented catalyst inhibition by the nitrile product. ${ }^{6}$ To further elucidate the role of byproducts and additives in titanium(III) catalysis, we now report a kinetic study of their influence on the catalytic reductive ketone-nitrile coupling reaction that was developed earlier in our labs. ${ }^{5 \mathrm{~b}, \mathrm{~d}}$ Using profiling and modeling techniques in combination with experimental and computational results, hidden pathways and equilibria are
Scheme 1. Titanium(III)-Catalyzed Reactions Showing a Beneficial Influence of Added Zinc Chloride

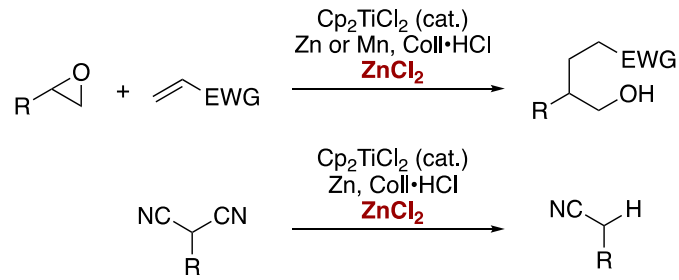

uncovered that are of broader relevance to low-valent titanium catalysis. 9

The reductive cross-coupling between acetophenone and benzyl cyanide proceeds in the presence of titanocene dichloride (1) or bis-ethylated catalyst 2 , zinc, triethyl amine hydrochloride, and TMS chloride in THF (Scheme 2a). The primary product is $\alpha$-trimethylsiloxyimine 3 , which is converted into hydroxyketone 4 during workup. The reaction stoichiometry further reveals that one equivalent of $\mathrm{ZnCl}_{2}$ and $\mathrm{Et}_{3} \mathrm{~N}$ are formed as byproducts. The reaction can be conveniently monitored by in situ IR, and we have previously established a mechanistic picture on the basis of experimental and theoretical investigations, including the reaction orders in substrates, additives, and catalysts. ${ }^{5,10}$ In a nutshell, the

Received: June 26, 2021

Revised: August 19, 2021

Published: August 31, 2021 
Scheme 2. Titanium-Catalyzed Reductive Coupling of Acetophenone and Benzyl Cyanide ${ }^{a}$
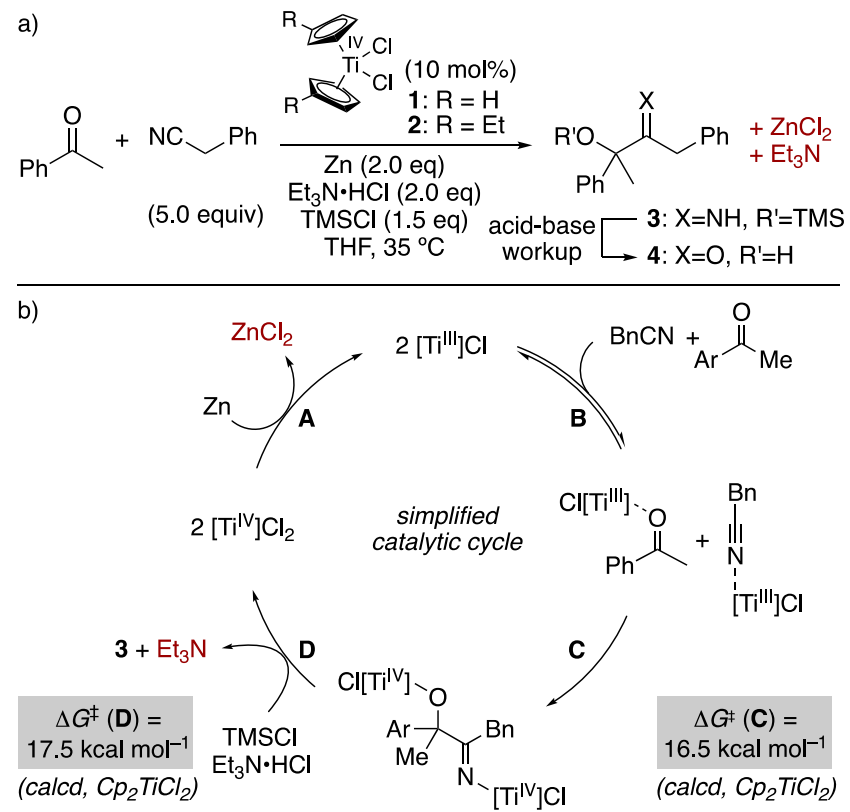

a (a) Reaction equation and stoichiometry. (b) Simplified catalytic cycle.

reaction starts with the reduction of two catalyst equivalents (A) Scheme 1b), which is followed by the reversible coordination of the nitrile and ketone coupling partners to one catalyst equivalent each (B). Then, a bimolecular $\mathrm{C}-\mathrm{C}$ bond formation occurs from the two substrate-titanium(III) complexes (C). The product is liberated through $\mathrm{Ti}-\mathrm{O}$ cleavage by $\mathrm{TMSCl}$ and $\mathrm{Ti}-\mathrm{N}$ cleavage by $\mathrm{HNEt}_{3} \mathrm{Cl}(\mathrm{D})$. The activation barriers for the simplified steps $\mathbf{C}$ and $\mathbf{D}$ were calculated to be almost at the same level with values of 17.5 and $16.5 \mathrm{kcal} \mathrm{mol}^{-1}$ for the reaction with $\mathrm{Cp}_{2} \mathrm{TiCl}_{2}$ as the catalyst. This renders both steps potentially rate-limiting, depending on the concentrations of the involved species. In addition, experimental activation energies of $\Delta G_{\mathrm{Cp}_{2} \mathrm{TiCl}_{2}}^{\ddagger}=18.9$ $\mathrm{kcal} \mathrm{mol}{ }^{-1}$ and $\Delta G_{(\mathrm{EtCp})_{2} \mathrm{TiCl}_{2}}^{ \pm}=23.8 \mathrm{kcal} \mathrm{mol}^{-1}$ have been determined. $^{11}$ To follow our previous computational investigation $^{10 \mathrm{~b}}$ and for the sake of simplicity, only the reaction with $\mathrm{Cp}_{2} \mathrm{TiCl}_{2}$ as the catalyst will be discussed in the following.

The kinetic profile of the "standard reaction" with conditions as given in Scheme 2a is shown in Figure 1a, which illustrates the decline in the concentration of acetophenone (determined by in situ IR from the $\mathrm{C}=\mathrm{O}$ stretch) as well as the increase of the imine stretch of 3 over time. An overlay of the
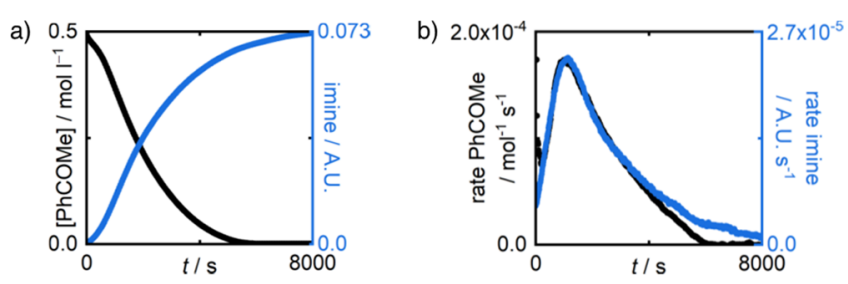

Figure 1. Kinetic profile of the reaction shown in Scheme 1 with $\mathbf{1}$ as the catalyst. (a) Concentration of acetophenone and the imine product $v s$ time. (b) Overlay of the rates of acetophenone consumption and imine formation vs time. corresponding plots of the reaction rate against time for the ketone consumption and imine formation shows a good match of the curves (Figure 1b). Here, two striking features of the catalysis are directly visible: (1) the imine formation still continues after the ketone consumption has completed. (2) An acceleration phase is present, which could stem from a product acceleration of an initially rate-limiting step until another step becomes rate-limiting (once $v_{\max }$ is reached). This could in turn be the result of a reservoir of inactive catalyst and/or substrate species that get reactivated by a product of the catalysis (autoinduction), or a true autocatalytic process, for example. 9

Regarding potential catalyst reservoirs, it is known from epoxide opening reactions that $\mathrm{HCollCl}$ (Coll $=2,4,6$ collidine) and $\mathrm{HNEt}_{3} \mathrm{Cl}$ can reversibly coordinate to $\mathrm{Cp}_{2} \mathrm{Ti}^{\mathrm{iII}} \mathrm{Cl}$, forming an off-cycle adduct (Scheme 3$){ }^{7 \mathrm{c}, \mathrm{d}}$

Scheme 3. Simplified Scenario of Active and Inactive Titanium(III) Species ${ }^{a}$

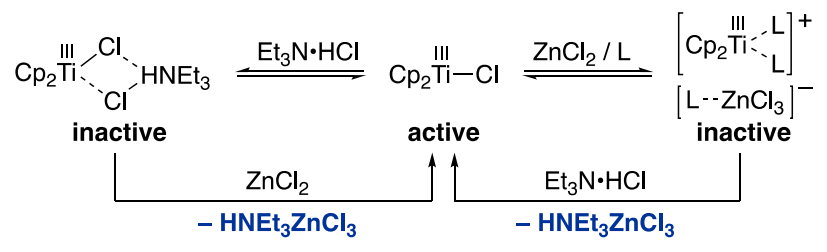

$\mathrm{L}=$ ketone, nitrile, $\mathrm{THF}, \mathrm{Et}_{3} \mathrm{~N}$

${ }^{a}$ Formation of energetically favorable $\mathrm{HNEt}_{3} \mathrm{ZnCl}_{3}$ from $\mathrm{HNEt}_{3} \mathrm{Cl}$ and $\mathrm{ZnCl}_{2}$ prevents catalyst deactivation.

Strongly coordinating solvents and substrates (e.g. $\mathrm{BnCN}$, $\mathrm{MeCN}$, or $\mathrm{H}_{2} \mathrm{O}$ ), on the other hand, promote the formation of cationic complexes, in particular, if $\mathrm{ZnCl}_{2}$ or other Lewis acids that abstract the remaining chloride from the titanium(III) center are present in excess. ${ }^{6 a, 12}$ Our investigations by cyclic voltammetry and DFT calculations further revealed that the combination of hydrochloride additive and $\mathrm{ZnCl}_{2}$ leads to a balance between the low-valent titanium species and increases the amount of the active titanium(III) chloride catalyst. ${ }^{6 a, 13}$ It was suggested that this is due to the energetically favored formation of the corresponding ammonium trichlorozincate (here: $\mathrm{HNEt}_{3} \mathrm{ZnCl}_{3}$ ). This $\mathrm{ZnCl}_{2}-\mathrm{HNEt}_{3} \mathrm{Cl}$ adduct is also a potential proton source and, in contrast to $\mathrm{HNEt}_{3} \mathrm{Cl}$ itself, it is well-soluble in THF. Because the amount of $\mathrm{ZnCl}_{2}$ increases over time, this could then result in a product acceleration of step D (vide infra).

\section{RESULTS AND DISCUSSION}

To further elucidate the role of the reaction byproducts as well as the hydrochloride additive, we monitored a series of modified ketone-nitrile coupling reactions by in situ IR and all curves shown in the following are the average of two experiments. ${ }^{13}$ The conclusions from visual inspection of the kinetic traces together with our previous results were then used to derive a kinetic model. It turned out that the role of the byproducts, in particular the one of $\mathrm{ZnCl}_{2}$, was more complex.

Qualitative Kinetic Analysis. First, we probed for potential catalyst deactivation and product inhibition by same excess experiments (Figure 2). A reaction was carried out in which the amount of all components except the catalyst (namely, ketone, nitrile, hydrochloride, chlorotrimethylsilane, and zinc) was reduced by 0.5 equiv of the initial concentration 
a)

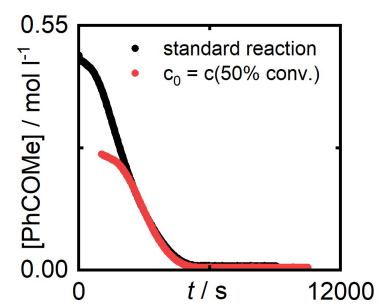

c)

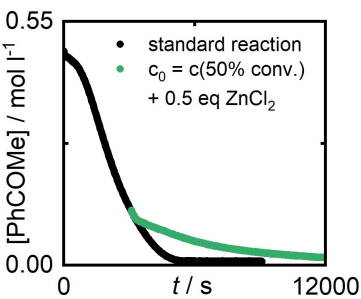

b)

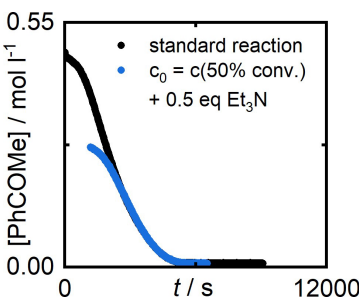

d)

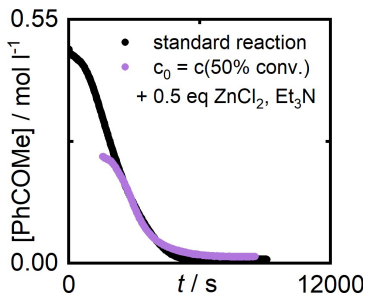

Figure 2. Same excess experiments with (a) $50 \%$ of the initial concentration in PhCOMe and the amounts of $\mathrm{BnCN}, \mathrm{HNEt}_{3} \mathrm{Cl}$, $\mathrm{TMSCl}$, and $\mathrm{Zn}$ reduced by an equimolar amount; (b) as (a) with additional 0.5 equiv $\mathrm{Et}_{3} \mathrm{~N}$; (c) as (a) with 0.5 equiv $\mathrm{ZnCl}_{2}$; (d) as (a) with 0.5 equiv of $\mathrm{ZnCl}_{2}$ and $\mathrm{Et}_{3} \mathrm{~N}$ added each. The standard reaction is shown as the black curve in graphs $(\mathrm{a}-\mathrm{d})$.

in ketone (Table 1). This way, the excess of each component over acetophenone remained the same and a point in the reaction was simulated at which $50 \%$ of the ketone and equimolar amounts of the other components were consumed. The curve of this reaction was brought to very good overlay with the standard reaction by time adjustment (Figure 2a). The experiment was repeated in the presence of additional 0.5 equivalents of the byproduct triethylamine, which again led to a very good overlay of the curves (Figure $2 b$ ). The addition of 0.5 equiv of the byproduct $\mathrm{ZnCl}_{2}$, on the other hand, led to a stark decrease in observed reaction rate after a small phase of rapid ketone consumption (Figure 2c). In general, the visible ketone concentration was significantly lower in comparison to the previous same excess experiments and no initiation phase was visible. Interestingly, carrying out this experiment with additional 0.5 equiv of triethylamine present led to a recovery of the reactivity (Figure $2 \mathrm{~d}$ ).

This inhibiting effect of $\mathrm{ZnCl}_{2}$ and the cancelation of it by added $\mathrm{Et}_{3} \mathrm{~N}$ was further investigated by experiments with added zinc chloride (1.0 equiv) in the absence and presence of $\mathrm{Et}_{3} \mathrm{~N}$ (1.0 equiv). As visual inspection of the ketone and imine traces shows (Figure 3a,b), the addition of 1 equiv of zinc chloride significantly reduced the ketone concentration at the beginning of the reaction and led to an absence of an initiation phase. The consumption of the remaining ketone and the imine formation were significantly slower. The addition of triethylamine decreased the initial drop in ketone concentration and the initiation phase became visible again. But the catalytic activity was only marginally restored as was indicated

a)

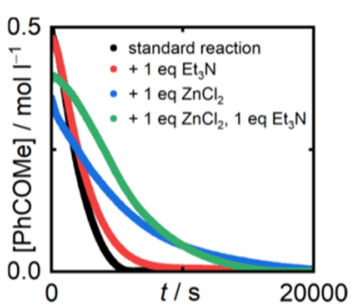

c)

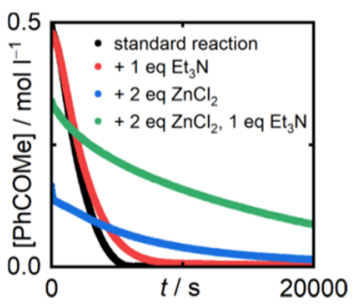

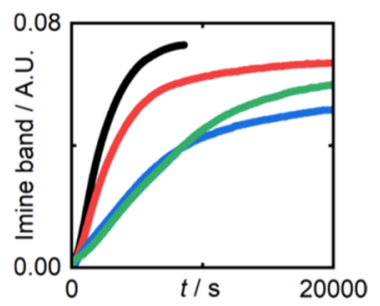

d)

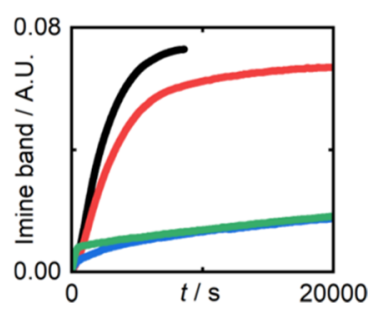

Figure 3. $(\mathrm{a}, \mathrm{b})$ Comparison of the influence of triethylamine (1 equiv), zinc chloride ( 1 equiv), and a combination of both. (c,d) Comparison of the influence of triethylamine (1 equiv), zinc chloride ( 2 equiv), and a combination of both.

by the still reduced production formation. The addition of $\mathrm{Et}_{3} \mathrm{~N}$ alone, on the other hand, led to a similar sigmoid profile as observed for the standard reaction, with only slightly reduced product formation. Since the sigmoid character was retained, the acceleration phase did not stem from an acceleration of the silylation step through formation of the more reactive silylium reagent $\left[\mathrm{TMS}-\mathrm{NEt}_{3}\right]^{+} \mathrm{Cl}^{-}$. In the past, such adducts were discussed as active reagents in titanium(III)-catalyzed Barbier reactions. ${ }^{4 \mathrm{i}}$ The initial drop in ketone concentration was even further increased if 2 equiv of $\mathrm{ZnCl}_{2}$ were added (Figure 3c). But despite the ketone rapidly being consumed, the imine formation was even further reduced (Figure $3 \mathrm{~d}$ ). With $\mathrm{Et}_{3} \mathrm{~N}$ added in addition, the initial ketone concentration was restored almost to the level of the reaction with 1 equiv $\mathrm{ZnCl}_{2}$ as the additive. But, as before, the imine formation rate remained low.

A probable explanation is the formation of a zinc(II)-ketone complex that can be partially reversed by the addition of $\mathrm{Et}_{3} \mathrm{~N}$ (Scheme 4). This reversibility contradicts the $\mathrm{ZnCl}_{2}$-promoted

Scheme 4. Hypothesized Formation of a Substrate Reservoir

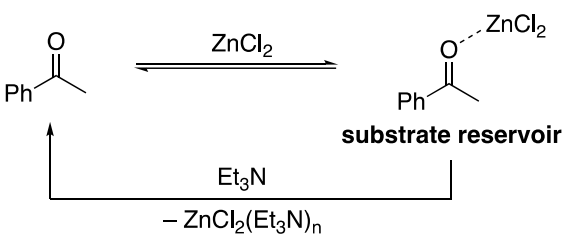

formation of the TMS silyl enol ether of acetophenone as a possible alternative scenario. Furthermore, a catalyst inhibition

Table 1. Molar Equivalents of the Components Varied in the Same Excess Experiments of Figure 2

\begin{tabular}{|c|c|c|c|c|c|c|c|}
\hline reaction & $\mathrm{PhCOMe}$ & $\mathrm{BnCN}$ & TMSCl & $\mathrm{HNEt}_{3} \mathrm{Cl}$ & $\mathrm{Zn}$ & $\mathrm{Et}_{3} \mathrm{~N}$ & $\mathrm{ZnCl}_{2}$ \\
\hline std (black) & 1.0 & 5.0 & 1.5 & 2.0 & 2.0 & 0 & 0 \\
\hline (a) (red) & 0.5 & 4.5 & 1.0 & 1.5 & 1.5 & 0 & 0 \\
\hline (b) (blue) & 0.5 & 4.5 & 1.0 & 1.5 & 1.5 & 0.5 & 0 \\
\hline (c) (green) & 0.5 & 4.5 & 1.0 & 1.5 & 1.5 & 0 & 0.5 \\
\hline (d) (violet) & 0.5 & 4.5 & 1.0 & 1.5 & 1.5 & 0.5 & 0.5 \\
\hline
\end{tabular}


by $\mathrm{ZnCl}_{2}$ took place, which could not be reverted by addition of $\mathrm{Et}_{3} \mathrm{~N}$. This was in agreement with the previously concluded formation of cationic titanium(III) species through chloride abstraction by $\mathrm{ZnCl}_{2}$ and coordination of a Lewis-basic component. $^{6 \mathrm{a}, 12}$

Next, we investigated the influence of triethylammonium trichlorizincate $\left(\mathrm{HNEt}_{3} \mathrm{ZnCl}_{3}\right)$ and $\mathrm{Et}_{3} \mathrm{~N}$ on the standard reaction (Figure 4). The presence of 1.0 equiv of $\mathrm{HNEt}_{3} \mathrm{ZnCl}_{3}$
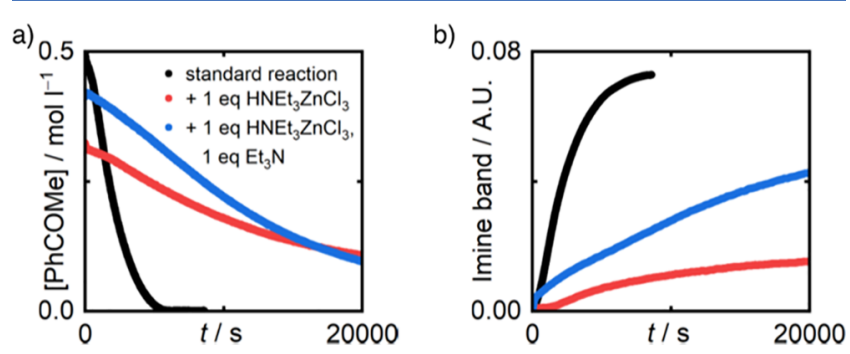

Figure 4. Influence of $\mathrm{HNEt}_{3} \mathrm{ZnCl}_{3}$ and $\mathrm{HNEt}_{3} \mathrm{ZnCl}_{3}$ in combination with $\mathrm{Et}_{3} \mathrm{~N}$. (a) Acetophenone concentration $v$ s time and (b) imine band intensity of the product $v$ s time.

led again to an initial drop in ketone concentration and a greatly reduced reaction rate, presumably because it served as a source of $\mathrm{ZnCl}_{2}$ and $\mathrm{HNEt}_{3} \mathrm{Cl}$, leading to substrate and catalyst inhibition. The formation of a white solid under these conditions, complicating the in situ IR measurements, supported this conclusion. As before, the presence of $\mathrm{Et}_{3} \mathrm{~N}$ reduced the ketone reservoir and, in this case, led to a partial recovery of the imine formation rate. Here, after an initially rapid increase in imine concentration, the progression was still slow in comparison to the standard reaction, which pointed toward a more complex equilibrium situation, still involving significant catalyst inhibition.

Derivation of a Kinetic Model Using COPASI. The above observations together with the conclusions from our earlier investigations were then used to assemble a kinetic network model of the reaction. Using the standard reaction and three selected reactions that accounted for the influence of
$\mathrm{Et}_{3} \mathrm{~N}, \mathrm{ZnCl}_{2}$, and $\mathrm{HNEt}_{3} \mathrm{Cl}$ each, the initial model was stepwise refined with the help of the free available complex reaction network modeling software COPASI. ${ }^{13,14}$ Fitting of the experimental data against the model was carried out using the parameter estimation feature with the Genetic Algorithm and Particle Swarm methods. Because the substrate consumption and product formation were not identical at all times, it was important to fit against the consumption of acetophenone and the formation of 3 . Whereas the concentration of acetophenone was obtained by calibration, the preliminary product 3 could not be prepared independently and calibrated against. Instead, $100 \%$ conversion of acetophenone into 3 was assumed and the monitored increase in imine was normalized accordingly. ${ }^{13}$ During the iterative optimizations of the model, several reactions were identified that were either instantaneous, unidirectional reactions or rapid equilibria. Here, several rate constants could be fixed to values of $10^{ \pm 6}$, which avoided linear dependencies. The fit against the final model was then finalized using the Particle Swarm algorithm with one million function evaluations.

For the following discussion of the model and the simulation results, it should be noted that among several alternatives tested, the current model is in best agreement with the conclusions from our experimental and theoretical studies. However, due to the large number of parameters fitted, the results require a careful interpretation and are compared with experimental and theoretical findings wherever possible. Furthermore, we focus the discussion on the relative values of the simulated parameters rather than the absolute values.

The final network model is given in Scheme 5. The central core system contained a simplified catalytic cycle comprising the non-reversible reductive $\mathrm{C}-\mathrm{C}$ coupling of ketone and nitrile in the presence of two equivalents of catalyst to give a product-catalyst complex $[\mathrm{cat}]_{2}$ prod $\left(k_{1}\right)$. This step was followed by the product release through protonation from $\mathrm{HNEt}_{3} \mathrm{ZnCl}_{3}\left(k_{2}\right)$. In addition, one equivalent of each triethylamine and $\mathrm{ZnCl}_{2}$ were released, the latter of which originated from the reduction of the two catalyst equivalents by $\mathrm{Zn}^{0}\left(\mathrm{Zn}^{0}\right.$ as the heterogeneous component was not

\section{Scheme 5. Schematic View of the Reaction Network Model Used for the Parameter Estimation ${ }^{a}$}

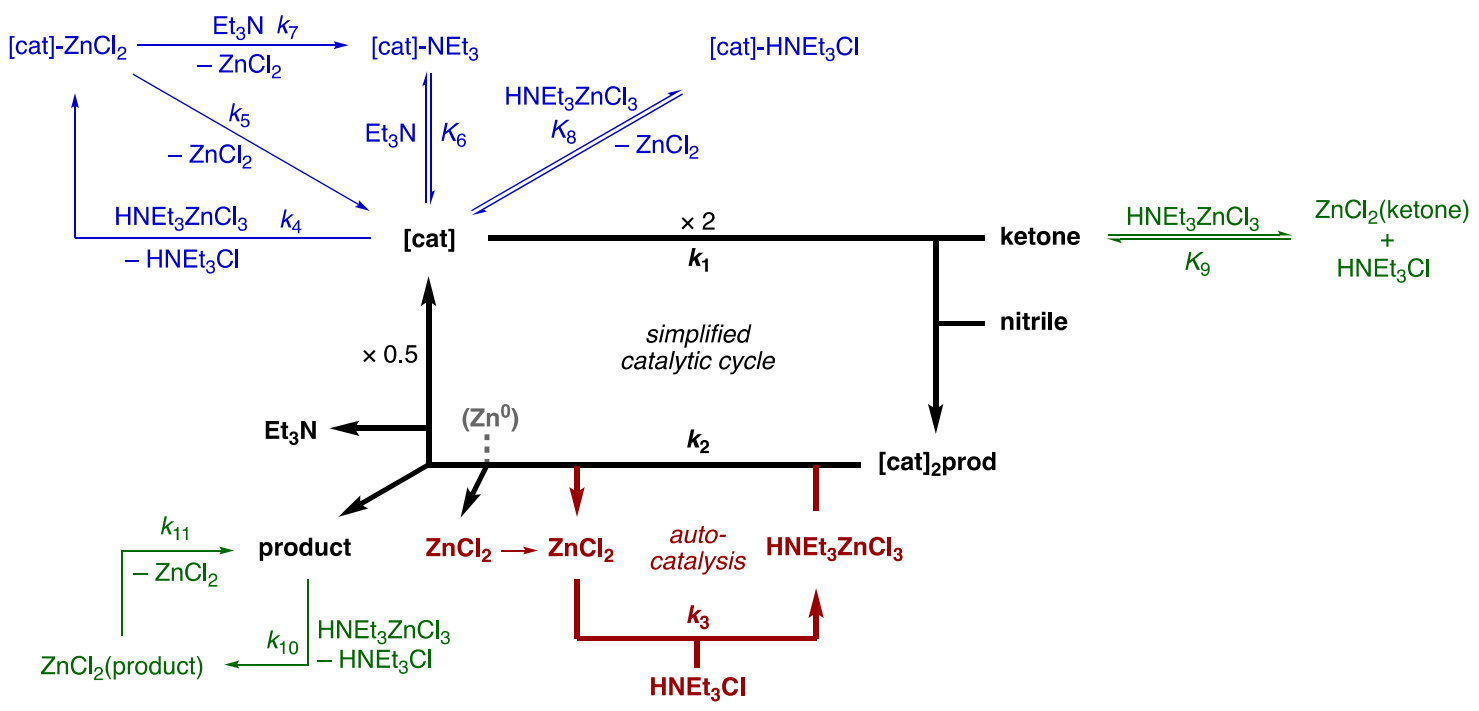

${ }^{a}$ Center: Simplified catalytic cycle for the ketone-nitrile coupling. Red: Autocatalytic cocatalysis by $\mathrm{ZnCl}_{2}$. Blue: Network of the involved off-cycle catalyst species. Green: Ketone and product reservoirs formed by the coordination to zinc chloride. 
included in the model). While, in theory, also a direct protonation by $\mathrm{HNEt}_{3} \mathrm{Cl}$ could have taken place, this pathway was found to be irrelevant and including it in the model led to undesired linear dependencies and an inferior fit. As confirmed by our earlier experiments, formation of $\mathrm{HNEt}_{3} \mathrm{ZnCl}_{3}$ from $\mathrm{HNEt}_{3} \mathrm{Cl}$ and $\mathrm{ZnCl}_{2}$ was rapid and quantitative $\left(k_{3}\right) .^{10 \mathrm{~b}}$ This resulted in a second catalytic cycle, in which $\mathrm{ZnCl}_{2}$ acted as a cocatalyst for the proton and chloride delivery from $\mathrm{HNEt}_{3} \mathrm{Cl}$ (red). Since turnover also increased the $\mathrm{ZnCl}_{2}$ concentration, this resulted in a hidden autocatalysis, which was responsible for the acceleration phase observed under the standard conditions and continuously accelerated the product release step $\left(k_{2}\right)$. Once the product release step became faster than the $\mathrm{C}-\mathrm{C}$ coupling step $\left(k_{1}\right)$, the latter became rate-determining and the expected decay in rate was observed. Attempts to achieve an equally good fit without this autocatalytic cycle (for example by modeling catalyst reservoirs only) were not successful.

The experimentally supported equilibria between several cationic and neutral titanium(III) catalyst species were taken into account as well (blue). As outlined in Scheme 3, the abstraction of a chloride by $\mathrm{ZnCl}_{2}$ led to a cationic titanium(III) complex, here denoted as [cat] $-\mathrm{ZnCl}_{2}$. During the refinement of the model, it was found that $\mathrm{HNEt}_{3} \mathrm{ZnCl}_{3}$ was the only source of $\mathrm{ZnCl}_{2}$ for the formation of [cat] $-\mathrm{ZnCl}_{2}$ $\left(k_{4}\right)$. This was in agreement with the strong driving force for the formation of $\mathrm{HNEt}_{3} \mathrm{ZnCl}_{3}$. In turn, the backreaction was found to be irrelevant. Instead, the direct liberation of [cat] and $\mathrm{ZnCl}_{2}$ from [cat]- $\mathrm{ZnCl}_{2}$ was found to be meaningful $\left(k_{5}\right)$. It was also important to include the formation of a catalysttriethylamine complex [cat]- $\mathrm{NEt}_{3}\left(K_{6}\right)$, which was also accessible from [cat] $-\mathrm{ZnCl}_{2}$ by displacement with $\mathrm{Et}_{3} \mathrm{~N}\left(k_{7}\right)$. The interaction of $\mathrm{Et}_{3} \mathrm{~N}$ with the titanium(III) catalyst is further supported by earlier reports of $\mathrm{Cp}_{2} \mathrm{Ti}^{\mathrm{III}} \mathrm{Cl}$ complexes of primary and secondary amines, for example, within the context of hydrogen atom transfer reactions. ${ }^{15}$ Although a corresponding complex $\mathrm{Cp}_{2} \mathrm{Ti}^{\mathrm{III}} \mathrm{Cl}\left(\mathrm{NEt}_{3}\right)$ has not been reported and a DFT calculation resulted in a positive Gibbs free energy of formation $\left(\Delta G=8.3 \mathrm{kcal} \mathrm{mol}^{-1}\right),{ }^{13}$ it was concluded to play a role in the current catalysis. The equilibrium of the titanium(III) catalyst with the aforementioned and literatureknown hydrochloride complex [cat]- $\mathrm{HNEt}_{3} \mathrm{Cl}$ was taken into account as well. Again, $\mathrm{HNEt}_{3} \mathrm{ZnCl}_{3}$ served as a source for $\mathrm{HNEt}_{3} \mathrm{Cl}$, whereas the direct formation of this complex from $\mathrm{HNEt}_{3} \mathrm{Cl}$ could be neglected.

Lastly, coordination complexes of zinc chloride were considered such as a ketone complex that served as a substrate reservoir (green). A similar product complex was suggested to be the cause of the observed deviation between ketone consumption and imine formation towards the end of the reaction (see Figure 1). The inclusion of the corresponding equilibrium and the unidirectional dissociation of this product complex $\left(k_{11}\right)$ were found to significantly improve the fit of the model. The dissociation of $\mathrm{ZnCl}_{2}$ (ketone), on the other hand, could be discarded. As before, $\mathrm{HNEt}_{3} \mathrm{ZnCl}_{3}$ served as the source of $\mathrm{ZnCl}_{2}$.

Overall, the whole network consisted of 11 reactions, only 3 of which were equilibria and 8 could be set as unidirectional. Removing any of the above reactions resulted in inferior fitting results and expanding the model to include the substratecatalyst coordination preequilibria did not further improve the outcome but led to linear dependencies (see Scheme 2, step B). The depicted model, however, does not yet comprise the observed prevention of the formation of a $\mathrm{ZnCl}_{2}$-ketone reservoir through added $\mathrm{Et}_{3} \mathrm{~N}$. Attempts to include relevant pathways into the model and to fit against reactions with multiple additives/byproducts rendered the network too complex to achieve satisfying and meaningful results.

The fitted curves and extracted parameters are given in Figure 5 and Table 2. An objective function value of $8.63 \times$

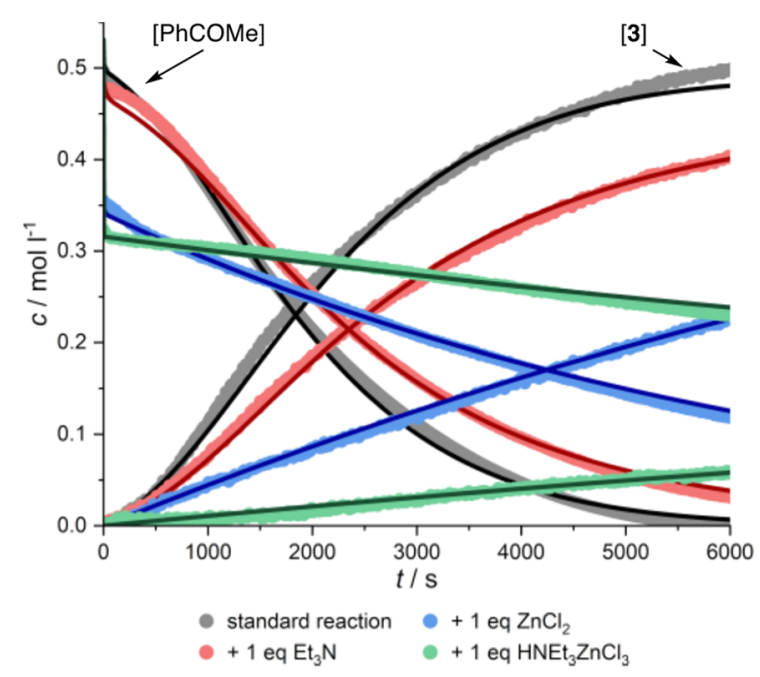

Figure 5. Experimental data (dots) and simulated curves (lines) for the consumption of PhCOMe and the formation of $\mathbf{3}$ for the standard reaction and reactions with $\mathrm{Et}_{3} \mathrm{~N}, \mathrm{ZnCl}_{2}$, and $\mathrm{HNEt}_{3} \mathrm{Cl}$ (1.0 equiv each).

$10^{-2}$ with an overall standard deviation of $5.2 \times 10^{-3}$ was achieved. The coefficients of variation for the fitted parameters were in the range of $1-8 \%$ with exception of the parameters for the $\mathrm{ZnCl}_{2}$-product complex formation that remained at a

Table 2. Parameter Estimation Results ${ }^{a}$

$\begin{array}{llll}\text { reaction } & \text { parameter (std. deviation) } & K & \text { gradient } \\ (1) & k_{1}=9.24(0.72) & -- & 7.60 \times 10^{-4} \\ (2) & k_{2}=0.804(0.013) & -- & 1.16 \times 10^{-2} \\ (3) & k_{3}=757(44) & -- & 4.55 \times 10^{-5} \\ (4) & k_{4}=1 \times 10^{6} & -- & \\ (5) & k_{5}=4.53(0.28) \times 10^{3} & -- & 7.41 \times 10^{-6} \\ (6) & k_{6}=1 \times 10^{6} & 5.32 & 1.75 \times 10^{-8} \\ & k_{-6}=1.88(0.11) \times 10^{5} & & \\ (7) & k_{7}=1.10(0.07) \times 10^{4} & -- & 1.72 \times 10^{-7} \\ (8) & k_{8}=1 \times 10^{6} & 8.70 & 1.24 \times 10^{-8} \\ & k_{-8}=1.15(0.05) \times 10^{5} & & \\ (9) & k_{9}=1 \times 10^{6} & 7.70 & 3.63 \times 10^{-8} \\ & & & \\ (10) & k_{10}=25.2(21.2) & -- & -1.92 \times 10^{-6} \\ (11) & k_{11}=6.51(5.48) & -- & -1.88 \times 10^{-8}\end{array}$

${ }^{a}$ All values are given for a reaction temperature of $308 \mathrm{~K}\left(35^{\circ} \mathrm{C}\right)$. Units have been omitted for clarity. The standard deviation is given in brackets. Fixed parameters are marked gray. 
higher uncertainty (84\%). A sufficient gradient convergence was achieved with the individual values, as shown in Table 2 .

Visual inspection showed that the simulated curves were in very good agreement with the experimental traces over a time frame of $6000 \mathrm{~s}$, the point at which all ketone was consumed under the standard reaction conditions. The sigmoidal character of the standard reaction and the reaction with additional 1.0 equiv $\mathrm{Et}_{3} \mathrm{~N}$ was reproduced by the fit. Extended times $(10,000 \mathrm{~s}$ and $20,000 \mathrm{~s})$ provided good results as well. ${ }^{13}$ The values received for $k_{1}$ and $k_{2}$ corresponded to activation barriers of $\Delta G^{\ddagger, 308 \mathrm{~K}}=16.7 \mathrm{kcal} \mathrm{mol}^{-1}$ and $\Delta G^{\ddagger 308 \mathrm{~K}}=18.2 \mathrm{kcal}$ $\mathrm{mol}^{-1}$, which were in excellent agreement with the previously calculated values for the $\mathrm{C}-\mathrm{C}$ coupling and the product release steps (see Scheme 2, steps $\mathbf{C}$ and $\mathbf{D}$ ). Moreover, the results were in agreement with the earlier determined experimental activation barrier of $\Delta G^{\ddagger}=18.9 \mathrm{kcal} \mathrm{mol}^{-1}$. ${ }^{10 \mathrm{~b}}$ The formation of the $\mathrm{ZnCl}_{2}-\mathrm{HNEt}_{3} \mathrm{Cl}$ adduct was several orders of magnitude faster and irreversible, the latter of which was supported by an earlier calculated negative free energy of formation of $\Delta G=-8.3 \mathrm{kcal} \mathrm{mol}^{-1},{ }^{10 \mathrm{~b}}$ and the observation that the addition of $\mathrm{ZnCl}_{2}$ led to rapid solvation of $\mathrm{HNEt}_{3} \mathrm{Cl}^{1{ }^{10 \mathrm{~b}}}$ The chloride abstraction by $\mathrm{ZnCl}_{2}$ (from $\left.\mathrm{HNEt}_{3} \mathrm{ZnCl}_{3}\right)$ to form a cationic titanium species $\left(k_{4}\right)$ as well as the formation and dissociation of the coordination complexes $\left(k_{ \pm 6}, k_{ \pm 8}\right.$, and $\left.k_{ \pm 9}\right)$ were found to be instantaneous. This corresponded to very low energy barriers for such coordination events, and the determined constants $K_{6}, K_{8}$, and $K_{9}$ showed that the equilibria were shifted toward the coordination complexes, both of which was expected. For the formation of [cat]- $\mathrm{HNEt}_{3} \mathrm{Cl}$, the extracted value of $K_{8}=8.71$ $\mathrm{mol}^{-1}$ corresponded to $\Delta G^{308 \mathrm{~K}}=-1.32 \mathrm{kcal} \mathrm{mol}^{-1}$, which was considerably higher than the theoretical value of $\Delta G^{298.15 \mathrm{~K}}=$ $-8.6 \mathrm{kcal} \mathrm{mol}^{-1}\left(K^{298.15 \mathrm{~K}}=2.0 \times 10^{6}\right)$ as calculated earlier by Gansäuer et al. ${ }^{7 \mathrm{~d}}$ It should be noted, however, that our value was indirectly determined by kinetic simulation.

Overall, we were delighted to find a good match between the fitted parameters $k_{1}$ and $k_{2}$ and the experimental activation barriers. Furthermore, the relative size and order of magnitude of the remaining rate constants as well as the simulated positions of the equilibria were in excellent agreement with our previous findings.

Using the fit parameters, a time course simulation of the concentrations of all involved catalyst intermediates under the standard reaction conditions was carried out (Figure 6). At the beginning of the reaction, most of the available catalyst is bound in form of the product complex $[\mathrm{cat}]_{2}$ prod due to the initially slow product release step. Upon reaction progress, more $\mathrm{ZnCl}_{2}$ is produced, which accelerates this step and leads to a decline of the $[\mathrm{cat}]_{2}$ prod intermediate and a buildup of the cationic complex [cat $]-\mathrm{ZnCl}_{2}$ and, later, [cat]- $\mathrm{NEt}_{3}$. The free neutral catalyst [cat] and the hydrochloride complex [cat]$\mathrm{HNEt}_{3} \mathrm{Cl}$ are minor species. The simulated scenario matched our previous online ESI-MS study, ${ }^{10 a}$ which showed the presence of mainly cationic titanium(III)-substrate and titanium(IV)-product complexes. This further supported the proposed model.

\section{CONCLUSIONS}

The kinetic analysis of the titanium(III)-catalyzed ketonenitrile cross-coupling reported herein gives important insights into the role of the additives and byproducts in low-valent titanium-catalyzed reactions. We propose that the byproduct $\mathrm{ZnCl}_{2}$ acts as a catalyst for the product release step through

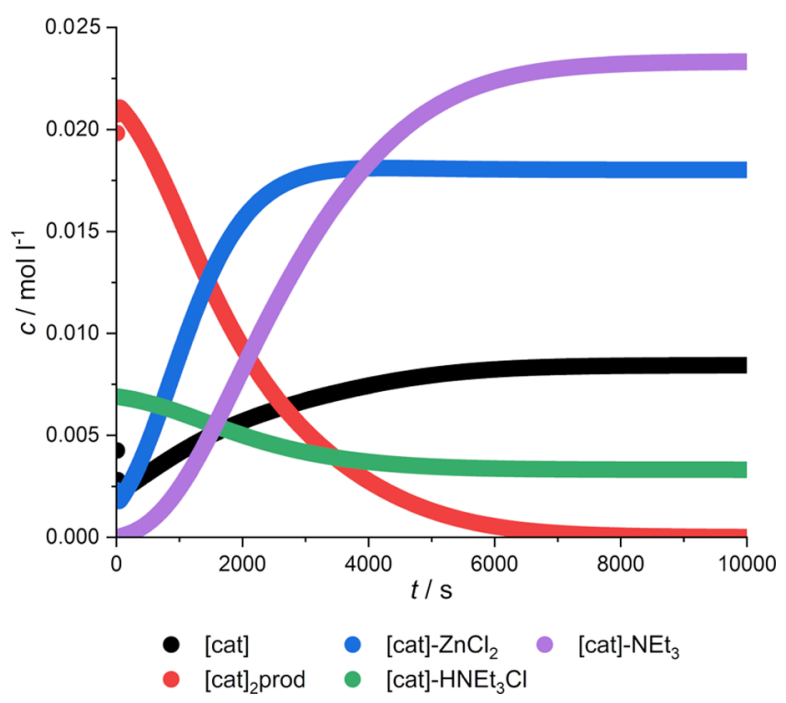

Figure 6. Simulated distribution of the catalyst species over the course of the standard reaction.

formation of $\mathrm{HNEt}_{3} \mathrm{ZnCl}_{3}$ as the active protonation agent. This leads to a hidden autocatalytic cycle and a change in the ratedetermining step over the course of the reaction. However, $\mathrm{ZnCl}_{2}$ also increases the presence of cationic titanium(III) species, which reduces the available amount of the active catalyst, and it can form a complex with acetophenone, which reduces the amount of the available substrate. In addition, the formation of an earlier proposed off-cycle titanium(III)$\mathrm{HNEt}_{3} \mathrm{Cl}$ coordination complex receives further support. Thus, the titanium catalyst, hydrochloride additive, and reaction byproducts form a well-balanced system, which upon addition of $\geq 1.0$ equiv $\mathrm{ZnCl}_{2}$ or $\geq 3.0$ equiv $\mathrm{HNEt}_{3} \mathrm{Cl}$ leads to reduced catalysis outcomes due to the formation of catalyst and substrate reservoirs. Overall, this study further completes the mechanistic picture of the titanium(III)-catalyzed ketonenitrile coupling reaction and, in a broader sense, it demonstrates the power of kinetic modeling to elucidate complex mechanisms in transition-metal catalysis, if it is carried out on the basis of experimental and theoretical results.

Moreover, this work improves the understanding of titanium(III)-catalyzed reactions in general. As we have shown, controlling the dynamic equilibria of the underlying reaction network by choice of the reaction conditions is important for achieving an efficient reaction. Likewise, other titanium(III)-catalyzed reactions depend on the adjustment of such equilibria by the careful choice of reducing agent, hydrochloride, and other additives. Their variation usually leads to a dramatic change in reaction performance. However, one has to be cautious to not easily extrapolate the conclusions from this study toward other reactions, because additives and the nature of the catalyst and reducing agent can have different effects depending on the type of reaction. One example is the influence of $\mathrm{ZnCl}_{2}$ as an additive as has been noted in the introduction. A second one is the control of the equilibrium between neutral and cationic titanium(III) complexes: while the latter have been established as off-cycle species in the ketone-nitrile coupling reaction, cationic titanium(III) catalysts have shown a superior performance in radical arylations of epoxides. $^{2 \mathrm{~b}, 16}$ 


\section{ASSOCIATED CONTENT}

\section{s) Supporting Information}

The Supporting Information is available free of charge at https://pubs.acs.org/doi/10.1021/acscatal.1c02870.

Experimental details, cyclic voltammetry experiments, details on kinetic model development and parameter estimation, computational details, COPASI report, and additional background (PDF)

Data collected in the in situ IR measurements (ZIP)

COPASI file and kinetic data input files (ZIP)

\section{AUTHOR INFORMATION}

\section{Corresponding Author}

Jan Streuff - Institut für Organische Chemie, Albert-LudwigsUniversität Freiburg, 79104 Freiburg, Germany; Department of Chemistry-BMC, Uppsala University, 75237 Uppsala, Sweden; (1) orcid.org/0000-0002-8320-4353;

Email: jan.streuff@kemi.uu.se

\section{Author \\ Sara L. Younas - Institut für Organische Chemie, Albert- Ludwigs-Universität Freiburg, 79104 Freiburg, Germany}

Complete contact information is available at: https://pubs.acs.org/10.1021/acscatal.1c02870

\section{Notes}

The authors declare no competing financial interest.

\section{ACKNOWLEDGMENTS}

This work was funded by the Deutsche Forschungsgemeinschaft (DFG, German Research Foundation), projects 275167197 and 408295365.

\section{REFERENCES}

(1) Selected reviews: (a) Gansäuer, A.; Justicia, J.; Fan, C.-A.; Worgull, D.; Piestert, F. Reductive C-C Bond Formation after Epoxide Opening via Electron Transfer. Top. Curr. Chem. 2007, 279, 25-52. (b) Streuff, J. Reductive Umpolung Reactions with LowValent Titanium Catalysts. Chem. Rec. 2014, 14, 1100-1113. (c) Streuff, J.; Gansäuer, A. Metal-Catalyzed $\beta$-Functionalization of Michael Acceptors through Reductive Radical Addition Reactions. Angew. Chem., Int. Ed. 2015, 54, 14232-14242. (d) Rosales, A.; Rodríguez-García, I.; Muñoz-Bascón, J.; Roldan-Molina, E.; Padial, N. M.; Morales, L. P.; García-Ocaña, M.; Oltra, J. E. The NugentRajanBabu Reagent: A Formidable Tool in Contemporary Radical and Organometallic Chemistry. Eur. J. Org. Chem. 2015, 4567-4591. (e) Beaumier, E. P.; Pearce, A. J.; See, X. Y.; Tonks, I. A. Modern applications of low-valent early transition metals in synthesis and catalysis. Nat. Rev. Chem. 2019, 3, 15-34. (f) McCallum, T.; Wu, X.; Lin, S. Recent Advances in Titanium Radical Redox Catalysis. J. Org. Chem. 2019, 84, 14369-14380.

(2) Selected recent works: (a) Chenniappan, V. K.; Silwal, S.; Rahaim, R. J. Ni/Ti Dual Catalytic Cross-Coupling of Nitriles and Organobromides To Access Ketones. ACS Catal. 2018, 8, 45394544. (b) Liedtke, T.; Spannring, P.; Riccardi, L.; Gansäuer, A. Mechanism-Based Condition Screening for Sustainable Catalysis in Single-Electron Steps by Cyclic Voltammetry. Angew. Chem., Int. Ed. 2018, 57, 5006-5010. (c) Wu, X.; Hao, W.; Ye, K.-Y.; Jiang, B.; Pombar, G.; Song, Z.; Lin, S. Ti-Catalyzed Radical Alkylation of Secondary and Tertiary Alkyl Chlorides Using Michael Acceptors. J. Am. Chem. Soc. 2018, 140, 14836-14843. (d) Zhang, Z.; Richrath, R. B.; Gansäuer, A. Merging Catalysis in Single Electron Steps with Photoredox Catalysis-Efficient and Sustainable Radical Chemistry. ACS Catal. 2019, 9, 3208-3212. (e) Yao, C.; Dahmen, T.; Gansäuer, A.; Norton, J. Anti-Markovnikov alcohols via epoxide hydrogenation through cooperative catalysis. Science 2019, 364, 764-767. (f) Ye, K. Y.; MCallum, T.; Lin, S. Bimetallic Radical Redox-Relay Catalysis for the Isomerization of Epoxides to Allylic Alcohols. J. Am. Chem. Soc. 2019, 141, 9548-9554. (g) Mülhaus, F.; Weißbarth, H.; Dahmen, T.; Schnakenburg, G.; Gansäuer, A. Merging Regiodivergent Catalysis with Atom-Economical Radical Arylation. Angew. Chem., Int. Ed. 2019, 58, 14208-14212. (h) Funk, P.; Richrath, R. B.; Bohle, F.; Grimme, S.; Gansäuer, A. Oxidation Under Reductive Conditions: From Benzylic Ethers to Acetals with Perfect Atom-Economy by Titanocene(III) Catalysis. Angew. Chem., Int. Ed. 2021, 60, 54825488. (i) Zhang, Z.; Stückrath, J. B.; Grimme, S.; Gansäuer, A. Titanocene-Catalyzed [2+2] Cycloaddition of Bisenones and Comparison with Photoredox Catalysis and Established Methods. Angew. Chem., Int. Ed. 2021, 60, 14339-14344.

(3) (a) Justicia, J.; Álvarez de Cienfuegos, L.; Campaña, A. G.; Miguel, D.; Jakoby, V.; Gansäuer, A.; Cuerva, J. M. Bioinspired terpene synthesis: a radical approach. Chem. Soc. Rev. 2011, 40, 3525-3537. (b) Morcillo, S. P.; Miguel, D.; Campaña, A. G.; Álvarez de Cienfuegos, L.; Justicia, J.; Cuerva, J. M. Recent applications of $\mathrm{Cp}_{2} \mathrm{TiCl}$ in natural product synthesis. Org. Chem. Front. 2014, 1, 1533. (c) Plesniak, M.; Huang, H.-M.; Procter, D. J. Radical cascade reactions triggered by single electron transfer. Nat. Rev. Chem. 2017, 1, 0077. (d) Martínez, A. R.; Morales, L. P.; Ojeda, E. D.; Rodríguez, M. C.; Rodríguez-García, I. The Proven Versatility of $\mathrm{Cp}_{2}$ TiCl. J. Org. Chem. 2021, 86, 1311-1329.

(4) Selected pioneering contributions: (a) Handa, Y.; Inanaga, J. A highly stereoselective pinacolization of aromatic and $\alpha, \beta$-unsaturated aldehydes mediated by titanium(III)-magnesium(II) complex. Tetrahedron Lett. 1987, 28, 5717-5718. (b) Nugent, W. A.; RajanBabu, T. V. Transition-metal-centered radicals in organic synthesis. Titanium(III)-induced cyclization of epoxy olefins. J. Am. Chem. Soc. 1988, 110, 8561-8562. (c) Fürstner, A.; Hupperts, A. Carbonyl Coupling Reactions Catalytic in Titanium and the Use of Commercial Titanium Powder for Organic Synthesis. J. Am. Chem. Soc. 1995, 117, 4468-4475. (d) Barden, M. C.; Schwartz, J. Stereoselective Pinacol Coupling in Aqueous Media. J. Am. Chem. Soc. 1996, 118, 5484-5485. (e) Gansäuer, A. Pinacol coupling of aromatic aldehydes catalysed by a titanocene complex: a transition metal catalysed radical reaction. Chem. Commun. 1997, 457-458. (f) Gansäuer, A.; Pierobon, M.; Bluhm, H. Catalytic, Highly Regioand Chemoselective Generation of Radicals from Epoxides: Titanocene Dichloride as an Electron Transfer Catalyst in Transition Metal Catalyzed Radical Reactions. Angew. Chem., Int. Ed. 1998, 37, 101-103. (g) Hirao, T.; Hatano, B.; Asahara, M.; Muguruma, Y.; Ogawa, A. $\mathrm{Cp}_{2} \mathrm{TiCl}_{2}$-Catalyzed pinacol-type coupling of aliphatic aldehydes by use of zinc and chlorosilane. Tetrahedron Lett. 1998, 39, 5247-5248. (h) Zhou, L.; Hirao, T. Stereoselective reductive radical cyclization of ketonitriles catalyzed by $\mathrm{Cp}_{2} \mathrm{TiCl}_{2}$ in the presence of chlorosilane and zinc. Tetrahedron 2001, 57, 6927-6933. (i) Rosales, A.; Oller-López, J. L.; Justicia, J.; Gansäuer, A.; Oltra, J. E.; Cuerva, J. $\mathrm{M}$. Unprecedented Barbier-type reactions catalysed by titanocene(iii). Chem. Commun. 2004, 2628-2629. (j) Estévez, R. E.; Oller-López, J. L.; Robles, R.; Melgarejo, C. R.; Gansäuer, A.; Cuerva, J. M.; Oltra, J. E. Stereocontrolled Coupling between Aldehydes and Conjugated Alkenals Mediated by $\mathrm{Ti}^{\mathrm{iII}} / \mathrm{H}_{2} \mathrm{O}$. Org. Lett. 2006, 8, 5433-5436.

(5) Selected works: (a) Streuff, J. A Titanium(III)-Catalyzed Redox Umpolung Reaction for the Reductive Cross-Coupling of Enones with Acrylonitriles. Chem.-Eur. J. 2011, 17, 5507-5510. (b) Streuff, J.; Feurer, M.; Bichovski, P.; Frey, G.; Gellrich, U. Enantioselective Titanium(III)-Catalyzed Reductive Cyclization of Ketonitriles. Angew. Chem., Int. Ed. 2012, 51, 8661-8664. (c) Frey, G.; Luu, H.-T.; Bichovski, P.; Feurer, M.; Streuff, J. Convenient Titanium(III)Catalyzed Synthesis of Cyclic Aminoketones and PyrrolidinonesDevelopment of a Formal [4+1] Cycloaddition. Angew. Chem., Int. Ed. 2013, 52, 7131-7134. (d) Feurer, M.; Frey, G.; Luu, H.-T.; Kratzert, D.; Streuff, J. The cross-selective titanium(III)-catalysed acyloin reaction. Chem. Commun. 2014, 50, 5370-5372. (e) Luu, H.-T.; Wiesler, S.; Frey, G.; Streuff, J. A Titanium(III)-Catalyzed Reductive Umpolung Reaction for the Synthesis of 1,1-Disubstituted Tetrahy- 
droisoquinolines. Org. Lett. 2015, 17, 2478-2481. (f) Bichovski, P.; Haas, T. M.; Kratzert, D.; Streuff, J. Synthesis of Bridged Benzazocines and Benzoxocines by a Titanium-Catalyzed DoubleReductive Umpolung Strategy. Chem.-Eur. J. 2015, 21, 2339-2342. (g) Frey, G.; Hausmann, J. N.; Streuff, J. Titanium-Catalyzed Reductive Umpolung Reactions with a Metal-Free Terminal Reducing Agent. Chem.-Eur. J. 2015, 21, 5693-5696. (h) Leijendekker, L. H.; Weweler, J.; Leuther, T. M.; Streuff, J. Catalytic Reductive Synthesis and Direct Derivatization of Unprotected Aminoindoles, Aminopyrroles, and Iminoindolines. Angew. Chem., Int. Ed. 2017, 56, 61036106.

(6) (a) Weweler, J.; Younas, S. L.; Streuff, J. Titanium(III)Catalyzed Reductive Decyanation of Geminal Dinitriles by a NonFree-Radical Mechanism. Angew. Chem., Int. Ed. 2019, 58, 1770017703. (b) Kern, C.; Selau, J.; Streuff, J. A Titanium-Catalyzed Reductive $\alpha$-Desulfonylation. Chem.-Eur. J. 2021, 27, 6178-6182.

(7) (a) Gansäuer, A.; Bauer, D. Novel Concept for Efficient Transition-Metal-Catalyzed Reactions: A Highly Diastereoselective Titanocene-Catalyzed Pinacol Coupling under Buffered Protic Conditions. J. Org. Chem. 1998, 63, 2070-2071. (b) Gansäuer, A.; Bluhm, H.; Pierobon, M. Emergence of a Novel Catalytic Radical Reaction: Titanocene-Catalyzed Reductive Opening of Epoxides. J. Am. Chem. Soc. 1998, 120, 12849-12859. (c) Gansäuer, A.; Behlendorf, M.; von Laufenberg, D.; Fleckhaus, A.; Kube, C.; Sadasivam, D. V.; Flowers, R. A., II Catalytic, Atom-Economical Radical Arylation of Epoxides. Angew. Chem., Int. Ed. 2012, 51, 47394742. (d) Gansäuer, A.; Kube, C.; Daasbjerg, K.; Sure, R.; Grimme, S.; Fianu, G. D.; Sadasivam, D. V.; Flowers, R. A., II Substituent Effects and Supramolecular Interactions of Titanocene(III) Chloride: Implications for Catalysis in Single Electron Steps. J. Am. Chem. Soc. 2014, 136, 1663-1671. (e) Gansäuer, A.; von Laufenberg, D.; Kube, C.; Dahmen, T.; Michelmann, A.; Behlendorf, M.; Sure, R.; Seddiqzai, M.; Grimme, S.; Sadasivam, D. V.; Fianu, G. D.; Flowers, R. A., II Mechanistic Study of the Titanocene(III)-Catalyzed Radical Arylation of Epoxides. Chem.-Eur. J. 2015, 21, 280-289. (f) Hilche, T.; Reinsberg, P. H.; Klare, S.; Liedtke, T.; Schäfer, L.; Gansäuer, A. Design Platform for Sustainable Catalysis with Radicals: Electrochemical Activation of $\mathrm{Cp}_{2} \mathrm{TiCl}_{2}$ for Catalysis Unveiled. Chem.-Eur. J. 2021, 27, 4903-4912.

(8) Gansäuer, A.; Bluhm, H. Dramatic rate acceleration in titanocene catalyzed epoxide openings: cofactors and Lewis acid cocatalysis. Chem. Commun. 1998, 2143-2144.

(9) For excellent introductory reviews on kinetic profiling and analysis, see: (a) Blackmond, D. G. Kinetic Profiling of Catalytic Organic Reactions as a Mechanistic Tool. J. Am. Chem. Soc. 2015, 137, 10852-10866. (b) Nielsen, C. D.-T.; Burés, J. Visual kinetic analysis. Chem. Sci. 2019, 10, 348-353. (c) For reviews on the kinetic modeling of homogeneous catalyses, see: Chaudhari, R. V.; Seayad, A.; Jayasree, S. Kinetic modeling of homogeneous catalytic processes. Catal. Today 2001, 66, 371-380. (d) Besora, M.; Maseras, F. Microkinetic modeling in homogeneous catalysis. Wiley Interdiscip. Rev. 2018, 8, No. e1372. (e) Motagamwala, A. H.; Dumesic, J. A. Microkinetic Modeling: A Tool for Rational Catalyst Design. Chem. Rev. 2021, 121, 1049-1076. (f) See also: Mower, M. P.; Blackmond, D. G. Mechanistic Rationalization of Unusual Sigmoidal Kinetic Profiles in the Machetti-De Sarlo Cycloaddition Reaction. J. Am. Chem. Soc. 2015, 137, 2386-2391.

(10) (a) Streuff, J.; Feurer, M.; Frey, G.; Steffani, A.; Kacprzak, S.; Weweler, J.; Leijendekker, L. H.; Kratzert, D.; Plattner, D. A. Mechanism of the $\mathrm{Ti}^{\mathrm{III}}$-Catalyzed Acyloin-Type Umpolung: A Catalyst-Controlled Radical Reaction. J. Am. Chem. Soc. 2015, 137, 14396-14405. (b) Streuff, J.; Himmel, D.; Younas, S. L. Understanding titanium-catalysed radical-radical reactions: a DFT study unravels the complex kinetics of ketone-nitrile couplings. Dalton Trans. 2018, 47, 5072-5082.

(11) The value for the reaction with $(\mathrm{EtCp})_{2} \mathrm{TiCl}_{2}$ was determined from $k_{\text {obs. }}$.

(12) (a) Seewald, P. A.; White, G. S.; Stephan, D. W. Cationic complexes of titanium(III); phosphine substitution reactions. Can. J.
Chem. 1988, 66, 1147-1152. (b) Gansäuer, A.; Behlendorf, M.; Cangönül, A.; Kube, C.; Cuerva, J. M.; Friedrich, J.; van Gastel, M. $\mathrm{H}_{2} \mathrm{O}$ Activation for Hydrogen-Atom Transfer: Correct Structures and Revised Mechanisms. Angew. Chem., Int. Ed. 2012, 51, 3266-3270.

(13) For details, see the Supporting Information.

(14) COPASI v4.31 (Build 243), available free of charge from http://www.copasi.org (accessed 2021-08-28). (b) Hoops, S.; Sahle, S.; Gauges, R.; Lee, C.; Pahle, J.; Simus, N.; Singhal, M.; Xu, L.; Mendes, P.; Kummer, U. COPASI-a COmplex PAthway SImulator. Bioinformatics 2006, 22, 3067-3074.

(15) (a) Paradas, M.; Campaña, A. G.; Jiménez, T.; Robles, R.; Oltra, J. E.; Buñuel, E.; Justicia, J.; Cárdenas, D. J.; Cuerva, J. M. Understanding the Exceptional Hydrogen-Atom Donor Characteristics of Water in $\mathrm{Ti}^{\mathrm{III}}$-Mediated Free-Radical Chemistry. J. Am. Chem. Soc. 2010, 132, 12748-12756.

(16) (a) Gansäuer, A.; Hildebrandt, S.; Michelmann, A.; Dahmen, T.; von Laufenberg, D.; Kube, C.; Fianu, G. D.; Flowers, R. A., II Cationic Titanocene(III) Complexes for Catalysis in Single-Electron Steps. Angew. Chem., Int. Ed. 2015, 54, 7003-7006. (b) Richrath, R. B.; Olyschläger, T.; Hildebrandt, S.; Enny, D. G.; Fianu, G. D.; Flowers, R. A., II; Gansäuer, A. $\mathrm{Cp}_{2}$ TiX Complexes for Sustainable Catalysis in Single-Electron Steps. Chem.-Eur. J. 2018, 24, 63716379. 